\title{
Enfrentando el bioterrorismo: aspectos epidemiológicos, clínicos y preventivos de la viruela
}

Carlos Franco-Paredes, MC, MPH, ${ }^{(1,2)} \mathrm{C}$ arlos del Río, MD, (2) Margarita N ava-Frías, MC, ${ }^{(1)}$ Sigfrido Rangel-Frausto, MC, MSC, ${ }^{(3)}$ Ildefonso Téllez, MC, ${ }^{(4)}$ José Ignacio Santos-Preciado, MD.(1)

\section{Franco-Paredes C, Del Río C, Nava-Frías M, \\ Rangel-Frausto S,Téllez I, Santos-Preciado Jl. Enfrentando el bioterrorismo: aspectos epidemiológicos, clínicos y preventivos de la viruela. Salud Publica Mex 2003;45:298-309. El texto completo en inglés de este artículo está disponible en: http://www.insp.mx/salud/index.html}

\section{Resumen}

Uno de los grandes logros de la salud pública mundial, la erradicación de la viruela, puede verse mermado por el posible riesgo de bioterrorismo. El debate acerca de la destrucción de los restos del virus en los dos laboratorios de referencia de la O rganización Mundial de la Salud ha cambiado diametralmente debido a los eventos terroristas y a la dispersión intencional de Bacillus anthracis ocurridos en poblaciones civiles en Estados U nidos de A mérica en el año 2001. La liberación del virus Variola con fines terroristas constituye un riesgo mínimo no cuantificable, pero desafortunadamente real. El impacto podría ser devastador debido a la elevada morbimortalidad de la enfermedad aunada al pánico y a la desestabilización social que podría ocasionar. Es por ello que el establecimiento de un plan de respuesta, sumado a disponibilidad de vacuna para ser utilizada posexposición, es importante dentro de los planes de contingencia contra el bioterrorismo. El reiniciar un programa limitado de vacunación contra la viruela, como parte de dicho plan, ha sido recientemente recomendado por el Comité Asesor de Vacunación, del Centro para el Control de las Enfermedades, pero la vacuna disponible puede causar complicaciones graves e incluso la muerte, por lo que dicha recomendación no ha sido universalmente aceptada. N 0 obstante, el personal médico y de salud pública requiere de
Franco-Paredes C, Del Río C, Nava-Frías M, Rangel-Frausto S, Téllez I, Santos-Preciado Jl. Confronting bioterrorism: Epidemiologic, clinical, and preventive aspects of smallpox. Salud Publica Mex 2003;45:298-309.

The English version of this paper

is available at: http://www.insp. mx/salud/index.html

\section{A bstract}

The worldwide eradication of smallpox, a major achievement in public health, is currently threatened by the risk of bioterrorism. The debate on the destruction of the Variola virus in the two reference laboratories of theW orld Health 0 rganization has dramatically switched to the preservation of the remaining virus after the September 2001 terrorist events in the U.S. along with the intentional release of Bacillus anthracis in the U.S. The risk of intentional release of Variola virus constitutes a minimal, yet possible risk. A smallpox epidemic could have a devastating impact due to its elevated morbidity and mortality that would inflict in nonimmune human population, in addition to the ensuing panic and social unrest. Therefore, the development of national preparedness and response plans along with the availability of smallpox vaccine to be used in the post-exposure phase represent a fundamental part of the preventive efforts to cope with bioterrorism. Reestablishing a preventive vaccination program was recently recommended by the $\mathrm{Ad}$ visory Committee on Immunization Practices (ACIP). However, the vaccine cur rently available has histo rically been associated with serious adverse reactions, even death.Thus, this recommendation has not been universally accepted. To counter an epidemic of smallpox, medical personnel in the frontline need to be prepared with updated smallpox infor-

(1) Centro N acional para la Salud de la Infancia y Adolescencia, Secretaría de Salud. México, DF, México.

(2) D epartamento de Medicina Interna, División de Enfermedades Infecciosas, Universidad de Emory, Atlanta, Georgia, Estados Unidos de América.

(3) Instituto $\mathrm{N}$ acional de las Ciencias Médicas y de la Nutrición, Salvador Zubirán. México, D F, México.

(4) Departamento de Medicina Interna, Hospital Angeles de Interlomas. México, D F, México.

Fecha de recibido: 7 de enero de 2003 - Fecha de aprobado: 14 de febrero de 2003 Solicitud de sobretiros: Carlos Franco Paredes. Centro N acional para la Salud de la Infancia y Adolescencia. Francisco P Miranda 177, 20. Piso, Colonia Merced Gómez. 01600 México, DF. Correo electrónico: cfranco@ sph.emory.edu 
información actualizada sobre la viruela y su prevención, ya que ellos son la primera línea de defensa en caso de un posible brote a consecuencia de un ataque bioterrorista. El presente artículo presenta una revisión dirigida a proporcionar al personal de salud un enfoque clínico, epidemiológico y preventivo sobre la viruela. El texto completo en inglés de este artículo está disponible en:http://www.insp.mx/ salud/index.html

Palabras clave: viruela; bioter rorismo; virus Variola; vacunación mation to identify, diagnose, isolate, and treat cases if a bioterrorist attack should occur. Herein we present an indepth review for health care personnel with relevant epidemiologic, clinical, and preventive information on smallpox. The English version of this paper is available at: http:// www.insp.mx/salud/index.html

Key words: smallpox; bioterro rism; Variola; vaccination

\section{Contexto actual del riesgo de bioterrorismo}

Antes de los eventos del 11 de septiembre de 2001, además del brote de ántrax ocasionado por la liberación intencional a través del sistema postal de Estados Unidos de América (EUA), pocos consideraban al bioterrorismo como un problema relevante de salud pública. ${ }^{1}$ Sin embargo, dichos eventos demostraron que la posibilidad de ataques bioterroristas es un riesgo latente en el ámbito global. La utilización de armas biológicas ya no es hoy en día una amenaza teórica, sino una realidad cuyo potencial destructivo es extremadamente elevado. Las características que ciertos agentes infecciosos poseen para ser considerados potencialmente como armas biológicas en poblaciones civiles incluyen: a) que causen elevada morbilidad y mortalidad; b) que se transmitan de persona a persona; c) que tengan una baja dosis infectante media; d) que sean altamente infectantes al ser diseminados como aerosol y, por tanto, tengan la capacidad para causar grandes brotes; e) que no exista una vacuna contra el agente o que ésta sea de disponibilidad limitada; f) que el agente en cuestión esté disponible; g) que exista el potencial para ser producido a gran escala, y h) que se trate de un agente estable en el medio ambiente. Los agentes que cumplen con estos criterios son denominados "clase A", y dentro de dicha categoría están: Bacillus anthracis, Clostridium botulinum, Yersinia pestis, Francisella tularensis, Variola major, y algunos de los virus causantes de fiebres hemorrágicas. ${ }^{2-8}$

El virus Variola causante de la viruela tiene una disponibilidad limitada, ya que luego de su erradicación sólo se reconoce su existencia en dos sitios: el Centro para el Control y la Prevención de las Enfermedades (CDC, por sus siglas en inglés) en Atlanta, EUA, y en el Centro Estatal de Investigaciones en Virología y Biotecnología en Koltsovo, Región de Novosibirsk de la
Federación Rusa. Sin embargo, se teme que otros países tengan también muestras de dicho virus, cuyo potencial destructivo es bien conocido debido al impacto que las diversas epidemias de viruela han tenido a lo largo de la historia de la humanidad. Estas epidemias han tenido una importante influencia demográfica en el establecimiento de las sociedades actuales, debido a sus elevadas morbilidad y mortalidad que la viruela ocasionó en poblaciones susceptibles. ${ }^{9}$ Se sabe que epidemias de viruela influyeron de manera muy importante en la conquista de los Imperios Inca y Azteca por los españoles. ${ }^{1,9,10}$ Gracias a la epidemia de viruela introducida por soldados españoles en el ejército Inca de Atahualpa, el ejército de Francisco Pizarro conformado por sólo 120 soldados, pudo derrotar a 80000 guerreros. ${ }^{10}$ De la misma forma, el ejército británico utilizó la viruela contra los nativos norteamericanos, cuando entregaron mantas que habían sido usadas por enfermos con viruela, diezmando a las tribus nativas de Norteamérica. ${ }^{8,10}$ Gracias al desarrollo de la vacuna contra la viruela realizado por Edward Jenner en 1796, el riesgo de que el agente causante de la viruela fuera utilizado como arma biológica disminuye considerablemente. $^{10}$

Apenas hace unos años la viruela se consideraba únicamente como una enfermedad con interés histórico. ${ }^{6}$ La última campaña de vacunación masiva contra la viruela organizada por la Organización Mundial de la Salud (OMS), y realizada entre los años 1966 a 1978, fue crítica para conseguir su erradicación y detener la transmisión entre humanos. ${ }^{11-14}$ Esta hazaña histórica, uno de los logros más significativos en la historia de la salud pública mundial, se ve actualmente amenazada ante la posibilidad de que el virus Variola pueda ser dispersado en forma intencional en poblaciones civiles con mínima inmunidad contra la enfermedad. ${ }^{5}$

La actual preocupación porque el virus causante de la viruela pueda ser usado como arma biológica de 
destrucción masiva es un riesgo mínimo, pero real. Debido al incumplimiento histórico de diversos gobiernos a los tratados de desmantelamiento de arsenales biológicos, y a la posible adquisición de estos agentes biológicos por grupos terroristas, que podrían utilizarlos para intimidar a gobiernos y sociedades, se ha provocado la necesidad de establecer planes estratégicos de respuesta ante un potencial ataque. ${ }^{6}$ Estas estrategias incluyen disponibilidad de vacuna antivariolosa, educación al personal de salud para la identificación y aislamiento de posibles casos, así como la activación del sistema de vigilancia y respuesta epidemiológica para el posible control de brotes de viruela. ${ }^{15-18}$

El objetivo de esta revisión es proporcionar información relevante para el personal de salud sobre los aspectos epidemiológicos y clínicos de la viruela, así como revisar las características de la vacuna antivariolosa y sus potenciales efectos adversos, con el fin de que el personal médico y de salud pública tenga información clara y actualizada sobre dicho padecimiento.

\section{El virus Variola}

El virus Variola pertenece al género Orthopoxvirus y a la familia Poxviridae. El género Orthopoxvirus incluye virus que contienen genomas de cadenas dobles de ADN, de aproximadamente 180 a 200 pares de kilobases, con más de 180 marcos de apertura de lectura (ORF's, por sus siglas en inglés). Morfológicamente estos virus son largos, en forma de ladrillo, y se diferencian de otros virus $\mathrm{ADN}$ en que se replican en el citoplasma celular, en lugar de hacerlo en el núcleo celular. ${ }^{11}$ La familia Poxviridae tiene dos subfamilias: Chordopoxvirinae, que infecta a animales vertebrados, $\mathrm{y}$ Entomopoxivirinae, que infecta a insectos. Existen cuatro miembros de la subfamilia Chordopoxvirinae capaces de infectar a humanos: a) virus Variola, b) virus Vaccinia, c) virus de la viruela bovina (cowpox), y d) virus de la viruela de los monos (monkeypox). ${ }^{5,11}$

El virus Vaccinia y el de la viruela bovina ocasionan infecciones localizadas en piel, mientras que el virus Variola y el virus de la viruela de monos causan enfermedades sistémicas. Sin embargo, mientras que la infección con el virus Variola ocurre únicamente en humanos, los otros tres pueden infectar tanto a humanos como a otros animales vertebrados. ${ }^{17,18}$

\section{Epidemiología}

Se calcula que el virus de la viruela emergió para infectar a las poblaciones humanas aproximadamente 10000 años a.c., correspondiendo a los comienzos del sedentarismo de las diversas poblaciones y a su consecuen- te organización en comunidades de agricultores. ${ }^{9-12} \mathrm{La}$ viruela persistió a lo largo de la historia de la humanidad tanto en formas endémicas y epidémicas cuando las poblaciones susceptibles eran suficientemente grandes como para permitir la circulación del virus. Debido a que no existen reservorios animales en la naturaleza, la persistencia del virus dependía de la continua transmisión entre humanos. ${ }^{9,11}$

La transmisión del virus Variola ocurre a través de gotas generadas en las mucosas oral, nasal y faríngea de pacientes infectados, y que, subsecuentemente, son inhaladas por personas susceptibles. La mayoría de los casos de transmisión resultan por contacto cercano cara a cara, con una persona infectada $y$, frecuentemente, dentro de una distancia menor a dos metros, o por el contacto físico con una persona infectada o a través de fomites contaminados. ${ }^{11,12,17,18}$

El virus también se ha encontrado en importantes concentraciones en las costras de pacientes infectados. Sin embargo, se considera que el contagio a través de esta vía es casi nulo, debido a que el virus se encuentra fuertemente adherido a la matriz fibrinosa. Otro importante método de transmisión fue la antigua práctica de la variolización, consistente en la inoculación en la piel de material proveniente de pústulas o restos de las lesiones cicatrizales de pacientes con viruela. ${ }^{11,12}$

Una persona infectada con el virus Variola no se considera infecciosa durante el periodo de incubación e inclusive durante los primeros días del estadio prodrómico. El paciente comienza su periodo de transmisibilidad con la aparición del exantema que se inicia con lesiones en boca y faringe. La transmisión es mucho más frecuente al momento de la aparición del exantema, y durante la primera semana, cuando las lesiones son vesiculares y pustulares. Las tasas de ataque en contactos son de 50 a $60 \%$. Existen variaciones temporales, similares a las del sarampión y la varicela, que ocurren principalmente durante el invierno y la primavera. ${ }^{11,12,17,18}$ Obviamente, este patrón no aplica en caso de un ataque por liberación intencional clandestina.

La transmisión natural de la viruela en una población determinada es baja. Existe un intervalo de dos a tres semanas en cada generación de casos. La viruela generalmente se disemina menos rápido que la varicela o el sarampión, debido a que la transmisión del virus Variola no ocurre sino hasta el momento de la aparición del exantema. Al mismo tiempo, al momento de aparición del exantema la mayoría de los pacientes se encuentran confinados en cama, debido a la fiebre y, a la postración que son características del estadio prodrómico. En muchas ocasiones, los pacientes en estos estadios acuden a recibir atención médica y por ello son los frecuentes brotes intra-hospitalarios. ${ }^{18}$ 
Es por lo anterior que los casos secundarios ocurren principalmente en quienes han tenido contacto con personas infectadas nosocomial o intra-domiciliariamente. ${ }^{19,20}$

\section{Patogénesis}

Los viriones contenidos en secreciones provenientes de mucosas orofaríngeas y respiratorias ingresan a través de la orofaringe. La infección por el virus Variola se inicia cuando el virus entra en contacto con la mucosa respiratoria $u$ orofaríngea. No se conocen los receptores virales específicos, pero se sabe que el virus produce múltiples proteínas que favorecen la evasión del sistema inmune a través de la producción de proteínas solubles, que se unen a citocinas y quimiocinas, proteínas inhibidoras de caspasa y de protein kinasas celulares. ${ }^{11,17}$ El virus se multiplica en ganglios linfáticos regionales $y$, subsecuentemente, ocurre su diseminación a través de una viremia primaria que sucede 3 o 4 días después de la entrada del virus, el cual invade la médula ósea, el bazo, y los ganglios linfáticos periféricos. Una viremia secundaria ocurre 8 a 10 días después de la infección inicial, y coincide con los primeros síntomas prodrómicos, caracterizados por fiebre y postración.

El virus se concentra en vasos sanguíneos de la dermis y de las mucosas oral y faríngea. Esta infiltración ocasiona el exantema maculopapular característico que, posteriormente, evoluciona hacia vesículas y pústulas..$^{11,17,18}$ Por razones no determinadas, estas lesiones se concentran principalmente en la cara y partes distales de las extremidades. El enantema que aparece en la mucosa oral y en la faringe se ulcera fácilmente, liberando importantes concentraciones del virus en la saliva, lo cual sucede al mismo tiempo de la aparición del exantema. ${ }^{13}$

\section{Diagnóstico clínico}

Existen dos formas clínicas de la viruela causadas por la infección con el virus Variola. Las dos variedades se deben a diferentes cepas del virus, y se distinguen por propiedades biológicas específicas, tales como diferencias en las características de crecimiento en cultivos, y por la estructura del ADN. ${ }^{11,18}$ La viruela mayor era la única variedad clínica conocida hasta finales del siglo XIX con tasas de fatalidad superiores a $20 \% .{ }^{11}$ Durante el periodo de incubación, que es aproximadamente de 12 días, con un rango de 8 a 19 días, el paciente no presenta ningún síntoma. Sin embargo, es durante el estadio prodrómico o fase pre-exantema cuando se inician los síntomas que aparecen abruptamente: fiebre $\left(39-40{ }^{\circ} \mathrm{C}\right)$, cefalea, mialgias, postración, y frecuentemente, náusea, vómito y dolor de espalda. Finalmente, con la aparición del exantema en mucosa oral, la persona se vuelve infecciosa. ${ }^{11-13,17,18}$

\section{Viruela mayor}

Existen diversas variedades clínicas de la viruela mayor que fueron distinguidas por sus diferentes pronósticos y transmisibilidad. Dos clasificaciones surgieron, una por Dixon, en 1962 y otra por Rao en 1967.12,13 Ramachandra Rao describe más de 7000 casos de viruela en India y establece la clasificación que posteriormente es adoptada por el grupo científico de la OMS para la erradicación de la viruela. En esta clasificación existen cinco presentaciones clínicas: a) ordinaria, b) modificada, c) plana, d) hemorrágica, y e) viruela sine eruptione (cuadro I). Las complicaciones asociadas a las diversas formas de la viruela se resumen en el cuadro II. $12,13,18$

\begin{tabular}{|c|c|c|}
\hline $\begin{array}{l}\text { Modificada (en personas } \\
\text { previamente vacunadas) }\end{array}$ & Leve & $\begin{array}{l}\text { - El exantema es similar al } \\
\text { ordinario pero tiene un } \\
\text { curso clínico acelerado }\end{array}$ \\
\hline Plana (usualmente fatal) & Grave & $\begin{array}{l}\text { - Las pústulas permanecen } \\
\text { planas } \\
\text { - Usualmente confluente } 0 \\
\text { semiconfluente } \\
\text { - Variedad no común }\end{array}$ \\
\hline $\begin{array}{l}\text { Hemorrágica (usualmen- } \\
\text { te fatal) }\end{array}$ & Grave & $\begin{array}{l}\text { - Hemorragias diseminadas } \\
\text { en piel y mucosas } \\
\text { - Dos subtipos: } \\
\text { - Temprana: con exantema } \\
\text { purpúrico, } 100 \% \text { fatal } \\
\text { - Tardía: con hemorragias } \\
\text { hacia la base de las pústulas }\end{array}$ \\
\hline
\end{tabular}

* Adoptada por la O rganización Mundial de la Salud 


\begin{tabular}{|c|c|}
\hline \multicolumn{2}{|c|}{$\begin{array}{c}\text { Cuadro II } \\
\text { ComplicACIONES DE LA VIRUELA }\end{array}$} \\
\hline Complicación & Comentarios \\
\hline Infecciones bacterianas & $\begin{array}{l}\text { Complicación rara, la presencia de fie- } \\
\text { bre puede confundirse con proceso } \\
\text { primario }\end{array}$ \\
\hline Artritis & $\begin{array}{l}0 \text { curre en } 2 \% \text { de los casos y más común- } \\
\text { mente en infantes }\end{array}$ \\
\hline $\begin{array}{l}\text { Complicaciones respiratorias: } \\
\text { bronquitis, neumonitis o neu- } \\
\text { monía }\end{array}$ & $\begin{array}{l}0 \text { curren generalmente al octavo día del } \\
\text { proceso y pueden ser virales } 0 \text { bacte- } \\
\text { rianas secundarias }\end{array}$ \\
\hline Encefalitis & $\begin{array}{l}\text { Encefalomielitis desmielinizante, similar a } \\
\text { la que ocurre por infección por Vaccinia, } \\
\text { sarampión o varicela. Es un proceso au- } \\
\text { toinmune con desmielinización e infil- } \\
\text { trados perivenulares }\end{array}$ \\
\hline $\begin{array}{l}\text { Muerte (la mortalidad de vi- } \\
\text { ruela mayor es de } 30 \% \text {; la } \\
\text { mortalidad en niños menores } \\
\text { de un año de edad es } 40-50 \% ; \\
\text { la mortalidad de la viruela } \\
\text { menor es }<1 \% \text { ) }\end{array}$ & $\begin{array}{l}0 \text { curre generalmente entre los días } 10 \text { - } \\
16 \text {. La causa de muerte es secundaria a la } \\
\text { afectación de múltiples órganos. } 0 \text { tros } \\
\text { factores que contribuyen son la viremia, } \\
\text { el impacto de la respuesta inmune a la } \\
\text { infección y la acumulación de complejos } \\
\text { inmunes circulantes. La mortalidad de las } \\
\text { variedades hemorrágicas y planas es }>90 \%\end{array}$ \\
\hline
\end{tabular}

Viruela mayor, variedad ordinaria

La variedad ordinaria ocurre en más de $90 \%$ de los casos y se presenta en personas no vacunadas. El estadio prodrómico en este tipo es de gravedad variable. Para el tercer o cuarto día aparece un enantema en la cavidad orofaríngea, aproximadamente 24 horas antes de la aparición del exantema. Los títulos del virus en saliva son muy elevados, especialmente durante la primera semana. ${ }^{12,13,18} \mathrm{El}$ exantema aparece de 2 a 4 días después del inicio de la fiebre como pequeñas máculas en la cara, particularmente en la frente. Subsecuentemente, las lesiones aparecen en las porciones distales de las extremidades, para después diseminarse al tórax y al abdomen. El exantema invade todo el cuerpo en aproximadamente 24 horas. Para el segundo día del exantema, las máculas se convierten en pápulas elevadas. Entre el tercer y cuarto día las lesiones se transforman en vesículas que contienen un líquido opaco, que se transforma en turbio dentro de 24 a 48 hrs. Las lesiones típicamente están rodeadas de un halo eritematoso. Las vesículas distendidas frecuentemente tienen una depresión central o umbilicación, la cual persiste hasta el estadio pustular. En el sexto o séptimo día, todas las lesiones se han convertido a estadio pustular. Entre los días 7 y 10 las pústulas maduran y alcanzan el tamaño máximo y, para este momento, la fiebre vuelve a aparecer y continúa elevada durante los estadios vesiculares y pustulares, hasta la formación de costras. Las pústulas son elevadas, redondas, con líquido a tensión y firmes al tacto. Estas lesiones al involucrar la dermis adquieren la característica de lesiones profundas al tacto. ${ }^{12,13,18}$ Además, estas lesiones aparecen en olas, y consecuentemente en un área particular del cuerpo están en el mismo estadio de evolución. La distribución del exantema ocurre en forma centrífuga: lesiones confluentes en cara, en partes distales de extremidades. Las palmas y plantas también se encuentran frecuentemente afectadas. Con relación a la densidad del exantema esta variedad tiene tres subtipos, los cuales tienen implicaciones pronósticas (cuadro I). La fatalidad en los casos ordinarios confluentes es de aproximadamente $62 \% .{ }^{11-13,18}$

El líquido contenido en las pústulas es lentamente absorbido para que al final de la segunda semana comiencen a formarse costras. Durante la tercera semana los restos cicatrizales de las costras se empiezan a caer, dejando áreas de piel despigmentada y, eventualmente, importantes cicatrices. ${ }^{13}$

\section{Viruela mayor, variedad modificada}

Esta variedad ocurre principalmente en individuos previamente vacunados. El estadio prodrómico es menos grave que en el tipo ordinario. Generalmente no hay fiebre durante la evolución del exantema. Las lesiones en piel tienden a evolucionar más rápidamente y a ser más superficiales, y pueden no mostrar las características típicas del exantema. Las lesiones aparecen en menor número. Este tipo rara vez es mortal. Es fácil confundir esta variedad con la varicela. ${ }^{11-13,18}$

\section{Viruela mayor, variedad hemorrágica}

Esta variedad de la viruela es afortunadamente rara y se acompaña de sangrado de las membranas mucosas y dentro de la piel. En las series de Rao, esta variedad se presentó en $2 \%$ de los pacientes hospitalizados, principalmente en adultos y en mujeres embarazadas. ${ }^{13}$ El estadio prodrómico, el cual puede ser prolongado, se caracteriza por fiebre, cefalea intensa y dolor de espalda, palidez de cara y postración extrema. La fiebre es continua y las manifestaciones hemorrágicas aparecen, ya sea temprana o tardíamente en el curso de la infección. La aparición temprana se asocia con un curso fulminante, iniciando con hemorragias subconjuntivales, sangrado de boca y encías, petequias, epistaxis y hematuria. La muerte ocurre aproximadamente entre el quinto y séptimo día de la 
enfermedad, cuando apenas pocas lesiones maculares han aparecido. ${ }^{11,13,18}$

\section{Viruela mayor, variedad plana}

Se considera la variedad más maligna de la viruela y se denomina plana porque las lesiones permanecen sin elevarse. No se conoce por qué algunas personas desarrollan esta variedad de la infección pero, en las series de Rao, entre 5 a 10\% de los casos se manifiestan con este tipo. Los niños y las niñas presentaban esta variedad más frecuentemente que los adultos. El estadio prodrómico es grave y dura aproximadamente entre 3 y 4 días. Los síntomas constitucionales son severos y continúan aun después de la aparición del exantema. La fiebre es persistente y el enantema es destructivo. La evolución del exantema es muy lenta y, para el séptimo u octavo día, las lesiones son planas y aparecen inmersas profundamente en la piel, y contienen poco líquido a comparación de las que ocurren en el tipo ordinario, además de no sufrir umbilicación. Las lesiones, sin embargo, son suaves y pueden contener áreas hemorrágicas. Las complicaciones respiratorias en este tipo son comunes y la mortalidad es mayor que $95 \% .11,13,17,18$

\section{Viruela sine eruptione}

En ocasiones algunos individuos previamente vacunados que tienen contacto con pacientes infectados con viruela sufren de un cuadro febril, cefalea y dolor de espalda sin mayores complicaciones. El ataque usualmente mejora en 48 horas sin aparición de exantema. Este proceso se relaciona con un incremento en la titulación de anticuerpos y los pacientes no presentan riesgo de contagio para los demás.

\section{Diagnóstico diferencial}

La enfermedad que más se asemeja a la viruela es la infección primaria por el virus herpes Varicella-zoster, es decir, la varicela. Las tres principales características que permiten diferenciar a la viruela de la varicela son: a) la presencia de fiebre y otros síntomas prodrómicos en la viruela antes de la aparición del exantema, b) la distribución centrífuga del exantema en la viruela, y c) el hecho de que las lesiones en la viruela se encuentran en el mismo estadio de evolución. Otras condiciones que podrían considerarse en el diagnóstico diferencial son: el herpes zoster diseminado, reacciones de hipersensibilidad a fármacos, eritema multiforme, herpes simples diseminado, sarna y molusco contagioso. ${ }^{11-13,17,18}$

\section{Confirmación por laboratorio}

Si el clínico se encuentra ante un paciente que presenta lesiones sugestivas de viruela la prueba de laboratorio más importante es para descartar varicela, mediante fluorescencia directa en material obtenido de las lesiones. Este método utiliza anticuerpos marcados, y se considera altamente sensible y específico, pero depende de la adecuada recolección de material de las lesiones. ${ }^{17,18}$ Una vez que se ha descartado infección por Varicella-zoster la identificación de Orthopoxvirus puede ser hecha a través de microscopia electrónica del fluido contenido en secreciones vesiculares o pustulares, o por la detección de los cuerpos de Guarnieri por microscopia de luz en secciones de tejido. La diferenciación de los Orthopoxvirus identificados por microscopia electrónica se realiza a través de pruebas de ácidos nucleicos, como la reacción de la polimerasa en cadena ( $\mathrm{PCR}$, por sus siglas en inglés) o por cultivo, lo cual requiere de laboratorios de diagnóstico especializados. ${ }^{15-18}$ Las serologías también son útiles para confirmar la presencia de infección por el virus Variola $^{18}$

\section{Viruela menor}

La segunda variedad clínica de la viruela es la viruela menor, la cual produce una enfermedad menos grave y con una mortalidad menor a $1 \%$. Fue descrita inicialmente por Korte en Sudáfrica en donde la enfermedad había ocurrido por décadas, y era conocida como amaas, probablemente derivada de la palabra holandesa $m a$ sels, que describía al sarampión. ${ }^{13}$ La viruela menor también se conocía como alastrim en Suramérica, palabra derivada del portugués alastra, que significa diseminarse de lugar a lugar. ${ }^{13}$ La viruela menor fue reconocida como la forma prevalente de viruela en Europa, Suramérica y EUA. 11,13,18

Las observaciones de Mardsen en 1936 aportaron la mejor información concerniente a las formas de viruela menor. ${ }^{11,13} \mathrm{El}$ diagnóstico de la viruela menor dependía de la severidad de los brotes y de la mortalidad asociada a éstos. Además, los síntomas constitucionales eran usualmente menos severos, con exantemas similares a los de la viruela mayor. Sin embargo, el exantema consistía en lesiones más pequeñas, menor cantidad de líquido en las vesículas y pústulas y sin presentar umbilicación. Mardsen agrupó sus descripciones de acuerdo con el número de las lesiones y a su confluencia en cara. El 86\% de los pacientes con viruela menor presentaban menos de 100 lesiones en cara, mientras que únicamente $3 \%$ presentaban formas hemorrágicas o malignas. ${ }^{11,13,18}$ 


\section{Manejo médico}

La sospecha de un caso de viruela es una emergencia médica y de salud pública, por lo cual requiere del involucramiento de las organizaciones estatales o federales respectivas. El aislamiento respiratorio y de contacto es fundamental en los casos en los cuales se sospecha viruela. El manejo médico es principalmente de apoyo; evitar sobre-infección bacteriana y mantener estados adecuados de hidratación para evitar insuficiencia renal y disfunción de otros órganos. ${ }^{17} \mathrm{Se}$ ha sugerido también que, debido a la elevada pérdida insensible de líquidos por el exantema, estos pacientes sean manejados con protocolos para quemados, sobre todo cuando las lesiones sean confluentes.

Recientemente se ha sugerido que el antiviral cidofivir pudiera ser útil; sin embargo, hasta el momento no existe ninguna experiencia clínica en humanos confirmatoria de su efectividad. ${ }^{6,15,17,18,21,22}$ Este compuesto ha demostrado ser eficaz contra el virus de la viruela bovina (cowpox) en ratones y contra el virus de la viruela de los monos (monkeypox) en el modelo símico. Por lo anterior, en EUA el cidofivir se encuentra en el inventario farmacológico contra la viruela como medicamento en investigación y sin aprobación oficial por la Food and Drug Administration (FDA, por sus siglas en inglés) y únicamente utilizable como medida de control de emergencia en caso de un brote de viruela. Además, gracias a investigaciones recientes se ha comprobado que la efectividad del cidofivir en el modelo símico depende de la dosis del virus utilizada, lo cual ha demostrado que la protección posexposición sólo es conferida con dosis infectantes bajas del virus. ${ }^{21,22}$

Porque hasta el momento no existe experiencia clínica con el cidofivir, y es un fármaco que se administra por vía parenteral, con posible nefrotoxicidad, la creación de nuevos fármacos efectivos y seguros contra la viruela es fundamental. Existe en la actualidad un programa coordinado por la OMS para el desarrollo de medicamentos antivirales derivados químicamente del cidofivir que podrían ser utilizados por vía oral y con un mejor perfil de seguridad y mayor eficacia $^{21,22}$ (ver La importancia de la investigación de frontera con Orthopoxvirus para los planes de preparación contra el bioterrorismo).

\section{Prevención: vacunación}

Los primeros intentos para controlar la viruela ocurrieron en India y en China en el siglo IX e involucraban la insuflación de restos de cicatrices de lesiones de pacientes con viruela o la inoculación de este material en la piel de personas que no habían padecido viruela. ${ }^{11,12,20,23}$ Este procedimiento se denomina variolización, y de India y China se diseminó hacia todo el continente asiático, África y, a finales del siglo XVIII, a Europa y Norteamérica. Sin embargo, en muchos casos en lugar de proteger contra la viruela, este método producía la enfermedad. ${ }^{11}$

Fue entonces cuando Edward Jenner, en 1796, descubre que posterior a la inoculación de material proveniente de lesiones de viruela bovina se desarrollaba inmunidad protectora para viruela. Jenner denominó vacca (del latín) al material utilizado para este procedimiento, el cual resultó mucho más seguro que la variolización y su uso se expandió rápidamente por todo el mundo. Fue Louis Pasteur quien en honor de Edward Jenner, más tarde amplió el término para incluir la inoculación preventiva con otros agentes infecciosos. ${ }^{11-13}$

Después del siglo XIX el entusiasmo por la vacunación contra la viruela disminuye en algunas áreas por la dificultad de mantener la vacunación a través de la inoculación de brazo a brazo, y por el riesgo de sífilis adquirida a través de este método. ${ }^{23} \mathrm{~A}$ partir de 1864, el descubrimiento de que el virus Variola era capaz de crecer en el costado de ternera brinda la oportunidad de obtener mayores cantidades de una vacuna más segura. Sin embargo, no fue sino hasta después de la Primera Guerra Mundial cuando en Europa la viruela fue controlada, y hasta después de la Segunda Guerra Mundial cuando la transmisión fue detenida también en Norteamérica. ${ }^{11}$

En regiones tropicales y subtropicales la viruela continuó siendo una plaga hasta mediados del siglo XX. En 1940 comienza la producción a gran escala de vacuna liofilizada. ${ }^{11}$ Esto permitió una mejor oportunidad para el control de la viruela. En 1950 la Organización Panamericana de la Salud inicia un programa regional de erradicación, que para 1967 demostró ser exitoso, logrando erradicar la viruela del continente americano con excepción de Brasil. ${ }^{6,11-13}$ Mientras tanto, miembros del programa de control de la viruela de la ex Unión Soviética sugirieron a la OMS llevar a cabo un programa global de erradicación. Como resultado de este programa se lograron progresos moderados entre 1959 y 1966, pero fue hasta 1967 cuando el programa intensificado de erradicación de la viruela tuvo mayores resultados. Fue así como el último caso de viruela en el mundo fue el de Ali Maow Maalin a quien se le diagnosticó con viruela menor el 26 de octubre de 1977 en Somalia. Posteriormente, el 8 de mayo de 1980 la Asamblea Mundial de la Salud 
de la OMS certificó la erradicación global de la viruela, único padecimiento hasta ahora erradicado por el hombre. ${ }^{6,14}$

A partir de entonces, la OMS decidió el almacenamiento de aproximadamente 200 millones de dosis de vacuna contra la viruela pero, a principios de los años 90, por cuestiones financieras, la OMS se vio obligada a almacenar sólo 50 millones de dosis. ${ }^{21-22}$ En ese entonces se discutió ampliamente la posibilidad de destruir todas las reservas conocidas del virus Variola, pero debido a que EUA decidió mantener una muestra, por disposición de la OMS se acordó que sólo los dos laboratorios de referencia en el mundo mantuvieran los restos del virus Variola. ${ }^{3-6}$ El debate continuó para la subsecuente destrucción de los restos del virus en estos laboratorios, lo cual se había finalmente programado para diciembre de 2002. ${ }^{21-22}$ Como resultado de los eventos ocurridos en 2001 en EUA, y el posible riesgo de más ataques biológicos, el Comité Técnico Asesor en Investigación en Viruela, asignado por la Asamblea de Salud de la OMS, en su tercera reunión en diciembre de 2001, determinó posponer la fecha para la destrucción de los restos del virus Variola y así tener acceso a éste para investigación esencial y el desarrollo de pruebas diagnósticas, desarrollo de vacunas y antivirales. ${ }^{21} \mathrm{~A}$ pesar de que durante el año 2002 se realizaron grandes avances en investigación en viruela, el Comité juzgó oportuno, en la cuarta reunión en diciembre de 2002, continuar posponiendo la fecha, debido a la necesidad de mayor investigación básica antes de la destrucción de los restos del virus. ${ }^{22}$

De la misma forma, el plan estratégico de muchos países, incluyendo a México, consistió en la compra de vacuna a compañías farmacéuticas que reiniciaron su producción, así como el establecimiento de planes de respuesta de emergencia para el control de un posible ataque. , $21,22^{2}$ La vacuna actualmente disponible es la viva atenuada del virus Vaccinia, preparada en los años 80 de linfa de ternera con la cepa del virus Vaccinia proveniente del New York City Board of Health (NYCBOH, por sus siglas en inglés). ${ }^{22-24}$ La vacuna es liofilizada, y como diluyentes contiene glicerina y antibióticos, como polimixina B, estreptomicina, tetraciclina y neomicina; y pequeñas concentraciones de fenol, como preservativo. La vacuna se administra a través de 15 punciones en la piel, con aguja bifurcada. ${ }^{11,17,18}$ Estudios recientes han demostrado que la dilución (1:5) de este tipo de vacuna (Wyeth Dryvax) produce inmunogenicidad aceptable. Sin embargo, una vacuna desarrollada en cultivos celulares, producida por Acambis-Baxter (Acam 1000 y Acam 2000), está siendo evaluada en ensayos clínicos para su posible utilización. ${ }^{15,22}$
Inmunogenicidad y eficacia de la vacuna

La eficacia de la vacuna antivariolosa obtenida de linfa de becerro nunca ha sido estudiada en ensayos clínicos controlados. Sin embargo, existe suficiente evidencia de su efectividad a través de las campañas masivas de vacunación. La respuesta inducida con anticuerpos neutralizantes produce una protección cruzada contra otros Orthopoxvirus, y son detectables aproximadamente 10 días después de la vacunación primaria en 95\% de los individuos, y siete días después de la revacunación. Los anticuerpos neutralizantes con títulos de 1:10 persisten en $75 \%$ de las personas por 10 años después de recibir una segunda dosis de la vacuna, y por 30 años después de recibir tres dosis de la vacuna. 11,18

La vacunación antivariolosa provee una importante protección si es administrada después de la exposición al virus Variola. En estudios de contactos intradomiciliarios en Pakistán y en India, la eficacia posexposición ha sido estimada en $91 \%{ }^{11,18,24-26}$

\section{Complicaciones de la vacunación}

La vacuna contiene virus vivos que comienzan a replicarse en el sitio de la inoculación. ${ }^{25-27}$ La vacunación primaria puede producir inflamación y dolor en ganglios linfáticos axilares aproximadamente 3 a 10 días después de la vacunación, que pueden persistir por 2 a 4 semanas después de que la lesión producida por la vacuna ha sanado. La aparición de fiebre es común, ocurre en aproximadamente $70 \%$ de infantes, y es menos frecuente en adultos. El virus Vaccinia se puede identificar a los tres días de la inoculación, y la dispersión del virus a otras partes del cuerpo, por auto inoculación accidental, es la complicación más frecuente de la vacunación, lo cual constituye aproximadamente 50\% de todas ellas. Estudios realizados en 1968 demostraron que la autoinoculación accidental ocurre aproximadamente en una de cada 1890 personas de las que reciben la vacuna por primera vez. ${ }^{25}$

Otras complicaciones que se pueden presentar son exantemas eritematosos o urticariales, los cuales suelen aparecer dentro de los primeros días luego de la vacunación. Raramente la vacunación puede generar reacciones severas, como eritema multiforme o síndrome de Stevens-Johnson. ${ }^{11,18}$

Las complicaciones moderadas a severas incluyen el eczema vaccinatum, la vaccinia generalizada, la vaccinia progresiva, y la encefalitis posvacunal. Estas complicaciones son raras pero ocurren 10 veces más frecuentemente en personas que reciben la vacuna por primera vez que en las revacunadas; también son más 
frecuentes durante la infancia que en la edad adulta. Se discuten en el cuadro III. 3,11-13,17,18,20,25,27

Las estrategias de vacunación, contenidas en los planes de respuesta para contrarrestar un posible ataque bioterrorista con el virus Variola, generalmente se encuentran divididas en la vacunación preexposición y la vacunación posexposición. ${ }^{20,26-30}$ La vacunación contra la viruela, a pesar de considerarse altamente efectiva, trae consigo la posibilidad de eventos adversos en una era de la medicina en la que el número de personas inmunodeprimidas es mayor que en décadas anteriores, una situación muy diferente a la existente en 1947, cuando por última ocasión se llevó a cabo una campaña de vacunación masiva contra la viruela en EUA. ${ }^{11,13,20,26}$ Sin embargo, el gobierno del presidente Bush ha aceptado las recomendaciones del Comité Asesor en Vacunación del CDC (ACIP, por sus siglas en inglés), para la vacunación voluntaria de aproximadamente 500000 trabajadores de la salud, y así poder participar en la respuesta inicial luego de un eventual ataque con viruela. Los riesgos asociados a la vacunación, y posible transmisión nosocomial del virus Vaccinia, han generado un intenso debate en la comunidad médica de EUA, y algunos hospitales han rechazado el plan propuesto por el presidente con el argumento de que los riesgos inherentes a la vacunación, que pudieran ocurrir al personal de salud, y la posible transmisión nosocomial a pacientes o familiares de los vacunados, si bien son bajos, parecen ser, hoy en día, mayores al riesgo de que ocurra un ataque bioterrorista con viruela. ${ }^{31,32} \mathrm{Si}$ bien existen modelos matemáticos ${ }^{28}$ que apoyan el plan propuesto por el gobierno de los EUA, otros expertos argumentan que el riesgo de complicaciones excede la posibilidad de un

\section{Cuadro III
Complicaciones ASOCIADAS A LA VACUNACIÓn CONTRA LA VIRUELA}

\begin{tabular}{|c|c|c|}
\hline Complicación & Descripción & Frecuencia \\
\hline Autoinoculación accidental & $\begin{array}{l}\text { - Complicación más frecuente } \\
\text { - Sitios más comunes: cara, párpados, nariz, boca, genitales y recto. Las lesiones mejoran } \\
\text { espontáneamente }\end{array}$ & $\begin{array}{l}1 \text { en } 1890 \text { vacunados por } \\
\text { primera vez }\end{array}$ \\
\hline Eczema vaccinatum & $\begin{array}{l}\text { - Diseminación local o sistémica del virus Vaccinia en personas con historia de dermatitis } \\
\text { atópica y otros exantemas exfoliativos crónicos } \\
\text { - Ocurre tanto en pacientes con historia de dermatitis como en aquellos con dermatitis } \\
\text { activa } \\
\text { - O curre en contactos con historia de dermatitis con personas que hayan sido vacunadas } \\
\text { - Los casos más severos ocurren durante vacunación primaria }\end{array}$ & $\begin{array}{l}1 \text { en } 25000 \text { vacunados por } \\
\text { primera vez }\end{array}$ \\
\hline Vaccinia generalizada & $\begin{array}{l}\text { - Viremia por Vaccinia con lesiones vesiculosas o pustulosas en piel de regiones distantes al } \\
\text { sitio de inoculación } \\
\text { - Produce un exantema que se autolimita con daño residual leve } \\
\text { - Cuadros severos en pacientes inmunosuprimidos }\end{array}$ & $\begin{array}{l}1 \text { en } 4000 \text { vacunados por } \\
\text { primera vez }\end{array}$ \\
\hline Vaccinia diseminada & $\begin{array}{l}\text { - Conocida también como Vaccinia necrotizante. Es una reacción severa caracterizada por } \\
\text { necrosis en el área de inoculación, y frecuentemente con lesiones metastásicas } \\
\text { - Ocurre en pacientes con inmunodeficiencias celular o humoral } \\
\text { - La utilización de inmunoglobulina antiviruela en estos pacientes mejora } \\
\text { - Puede ser un problema mucho más importante por el gran número de pacientes con } \\
\text { infección por elVIH e inmunosuprimidos por drogas (trasplantes, cáncer) }\end{array}$ & $\begin{array}{l}1 \text { en } 600000 \text { vacunados por } \\
\text { primera vez }\end{array}$ \\
\hline Encefalitis posvacunal & $\begin{array}{l}\text { - O curre en infantes menores de } 12 \text { meses de edad y en adolescentes y adultos durante la } \\
\text { vacunación primaria } \\
\text { - Se presenta como ataxia, confusión, parálisis, convulsiones o coma } \\
\text { - Resulta de una reacción autoinmune y no por invasión del virus al sistema nervioso } \\
\text { central } \\
\text { - Mortalidad de } 15 \text { a } 25 \% \text { y } 25 \% \text { sobreviven con secuelas permanentes }\end{array}$ & $\begin{array}{l}1 \text { en } 800000 \text { vacunados por } \\
\text { primera vez }\end{array}$ \\
\hline Vaccinia fetal & $\begin{array}{l}\text { - Es una complicación rara después de la vacunación primaria en mujeres durante el pri- } \\
\text { mer semestre del embarazo } \\
\text { - Muerte fetal o muerte durante el periodo perinatal } \\
\text { - El virus Vaccinia no se ha asociado a malformaciones congénitas }\end{array}$ & Sólo 50 casos descritos \\
\hline Muerte & - Generalmente secundaria a encefalitis posvacunal o vaccinia progresiva & $\begin{array}{l}1 \text { en } 1000000 \text { de vacuna- } \\
\text { dos por primera vez, y } 1 \text { en } \\
4000000 \text { en revacunados }\end{array}$ \\
\hline
\end{tabular}


ataque de viruela. Por ejemplo, en una revisión reciente, Kent Sepkowitz demuestra la posibilidad de causar iatrogénicamente una epidemia del virus Vaccinia a través de la transmisión nosocomial del virus. ${ }^{27}$

Por otro lado, no existe controversia alguna respecto a la contención de un posible brote por medio de la vacunación posexposición de contactos, así como el adecuado aislamiento de pacientes infectados en lugares especialmente destinados para ello., 5, $17,20,26 \mathrm{Mo}-$ delos matemáticos desarrollados recientemente también han demostrado que la vacunación, dirigida a grupos específicos expuestos al virus, sería tan efectiva como la vacunación masiva de la población, en caso de un evento de bioterrorismo. ${ }^{30}$

\section{Epidemiología intrahospitalaria}

En caso de un brote de viruela aunado a la vacunación de los contactos, el aislamiento de pacientes y sus contactos es una estrategia fundamental para la contención del brote. La diseminación clandestina del virus podría producir la rápida transmisión de éste en poblaciones susceptibles, expandiéndose por un factor de 10 a 20 veces en cada generación de nuevos casos. ${ }^{11,18,20,26}$ Inmediatamente se considere el posible diagnóstico de viruela en un nivel intrahospitalario, el paciente debe ser aislado y todos los contactos intradomiciliarios y los más cercanos deben ser vacunados y colocados bajo vigilancia médica. Si los hospitales no tienen cuartos de aislamiento con presión negativa se deberán aislar los casos y contactos en sus domicilios o en lugares asignados, para evitar la diseminación y posible transmisión intrahospitalaria del virus a personas susceptibles. La vacunación posexposición dentro de los primeros cuatro días posteriores al contacto ha demostrado ofrecer protección contra la infección y, más importante aún, disminución de la severidad de la enfermedad. ${ }^{11,18}$

\section{La importancia de la investigación de frontera con Orthopoxvirus para los planes de preparación contra el bioterrorismo}

El contar con planes de respuesta contra el bioterrorismo y disponibilidad de la actual vacuna para lidiar efectivamente contra un posible brote de viruela no parece ser suficiente. La vacuna actualmente disponible es efectiva, pero se asocia potencialmente a efectos adversos con elevadas morbilidad y mortalidad. Asimismo, estas complicaciones podrían ser mayores en una etapa de la medicina clínica en la que el número de pacientes inmunocomprometidos o con trastornos de hipersensibilidad y alergias es importante y, por lo tanto, el riesgo de complicaciones por la vacunación o por viruela clínica podría ser superior a que lo previamente reportado. Es por lo anterior que aunado a los actuales planes de respuesta, la investigación para la creación de vacunas más seguras que conserven la misma efectividad, así como la disponibilidad de nuevos medicamentos antivirales que sean efectivos y seguros contra el virus Variola, constituye una prioridad en los programas globales de bioseguridad. ${ }^{21} \mathrm{El}$ desarrollo de pruebas diagnósticas sensibles y específicas para la detección oportuna del virus en casos clínicamente sospechosos sería una contribución invaluable..$^{21-22}$

De las 120 cepas del virus Variola que se encuentran en manos de la colección de contenidos en la Federación Rusa, 55 de ellas han sido seleccionadas para investigación, específicamente en estudios de viabilidad del virus, caracterización biológica y análisis genómico. Hasta el momento, 39 cepas han sido estudiadas, de las cuales 29 son viables. El análisis de las 451 cepas en la colección estadounidense demostraron que algunas de ellas eran virus de la viruela del mono, virus de la viruela de camello o variantes quiméricas entre varios Orthopoxvirus. El origen geográfico y el año de aislamiento de la cepa son conocidos para 229, y 50 de las cuales fueron seleccionadas para estudios de investigación, determinación del número de pases para la creación de vacunas y, de ellas, 46 demostraron ser viables. ${ }^{21,22}$

\section{Desarrollo de antivirales}

En relación con el desarrollo de medicamentos antivirales, el Comité Asesor de la OMS en Investigación en Viruela señaló, en la cuarta reunión realizada en diciembre de $2002,{ }^{22}$ que ambas instituciones que albergan los restos del virus, y diversas compañías farmacéuticas han identificado nuevos compuestos con actividad antiviral contra el virus Variola. La Federación Rusa ha estudiado 2432 compuesta con actividad inhibitoria viral, de los cuales identificaron seis que están siendo analizados en modelos animales. Investigadores de EUA, Gran Bretaña e Irlanda del Norte han identificado 40 promisorios compuestos, con gran actividad inhibitoria para el virus Variola.

\section{Desarrollo de vacunas}

La investigación en vacunas antivariolosas ha ocurrido principalmente en el Reino Unido, dirigidas especialmente a la creación de vacunas de segunda generación de subunidades virales, a través de la identificación de antígenos, potencialmente inductores de 
protección. Se están realizando estudios para evaluar la cepa modificada Ankara del virus Vaccinia como posible candidata para el desarrollo de vacuna de virus vivos atenuados. Otra línea de investigación, que se encuentra en sus primeras fases, constituye la elaboración de vacunas de $\mathrm{ADN}$ viral. ${ }^{22}$

Pruebas diagnósticas

Dificultades técnicas, como la producción de anticuerpos monoclonales específicos contra el virus Variola han dificultado la elaboración de métodos serológicos sensitivos para la detección de antígenos virales, por lo cual la investigación en esta área se ha basado principalmente en la creación de ensayos de PCR. Estudios realizados por los grupos de investigación ruso y estadounidense han demostrado ser el método de elección para la identificación del virus en muestras clínicas, y para la diferenciación del virus Variola de otros Orthopoxvirus. ${ }^{21,22}$

\section{Conclusiones}

Ante la remota, pero no inexistente, posibilidad de bioterrorismo, la mayoría de los gobiernos ha incluido este problema dentro de los primeros lugares de la agenda de salud pública. Esto hace indispensable volver a capacitar para el diagnóstico y manejo de casos. ${ }^{33,34} \mathrm{El}$ aislamiento de casos y contactos es la medida más importante para contener la diseminación de la enfermedad. Los autores consideramos que hoy el riesgo de complicaciones asociadas a la vacunación contra la viruela no justifica la utilización de la estrategia de vacunación preexposición sólo en personal de riesgo. La investigación utilizando los restos del virus Variola es fundamental para la creación de nuevas vacunas con un mejor perfil de seguridad, y para el desarrollo de antivirales efectivos y seguros contra la viruela.

\section{Referencias}

1. Del Río C, Franco-Paredes C. Bioterrorismo: un nuevo problema de salud pública. Salud Publica Mex 2001;43(6):585-588.

2. 0 'Toole T. Smallpox:An attack scenario. Emerg Infect $D$ is 1999;5(4):540-551.

3. Danzig R, Berkowsky PB.W hy should we be concerned about biological warfare? JAMA 1997:278(5):431-432.

4. Christopher GW, Cieslak TJ, Pavlin J, Eitzen EM. Biological warfare:A historical perspective. JAMA 1997:278(5):412-417.

5.Varkey P, Poland G, Cockerill F. Confronting bioterrorism: Physicians on the front line. Mayo Clin Proceed 2002;77:661-672.
6. Henderson DA. C ountering the posteradication threat of smallpox and polio. Clin Infect D is 2002;34:79-83.

7. Borio L, Inglesby T, Peters CJ. Hemorrhagic fever viruses as biological weapons: Medical and public health management. JAMA 2002:287(18):2391-2405.

8. Henderson DA, Inglesby TV, Bartlett J,A scher M, Eitzen E, Jahrling PB et al. Smallpox as a biological weapon: Medical and public health management. JAMA 1999;281(220):2127-2137.

9. McN eill W H. Plagues and peoples. Garden City (N Y):Anchor Press/ Doubleday, 1976.

10. Diamond J. Up to the starting line. G uns, Germs, Steel. The fates of human societies. N ew York (N Y):W W N orton and Company, 1999: 35-52.

11. Henderson DA, Moss B. Smallpox and vaccinia. En: Plotkin S, 0 renstein W, ed.Vaccines. Third Edition. Filadelfia (PA):W.B. Saunders Company, 1999:74-97.

12. Fenner F, Henderson DA, A rita I, Jezek Z, Ladvi ID. The epidemiology of smallpox. En: Fenner F, Henderson D.A.A rita I, Jezek Z, Ladvi ID, Ed. Smallpox and its eradication. Chapter 4. Ginebra:World Health O rganization, 1988.

13. Fenner $F$, Henderson DA, A rita I, Jezek Z, Ladvi ID. The clinical features of smallpox. En: Fenner F, H enderson D.A.A rita I, Jezek Z, Ladvi ID, Ed. Smallpox and its eradication. Chapter 1. G inebra, W orld Health 0 rganization, 1988.

14. World Health 0 rganization. Smallpox eradication:Temporary retention of variola virus stocks.W kly Epidemiol Record 2001;19: 142-145.

15. Centers for Disease Control. Strengthening national preparedness for smallpox:An update. Emerg Infect D is 2001;7(1):155-156. 16. Metlzer MI, Damon I, LeD uc JW, Millar JD. Modeling potential responses to smallpox as a bioterrorist weapon. Emerg Infect $D$ is 2001;7(6):1-19.

17. Centers for Disease Control.Vaccinia (smallpox) vaccine. Recommendations of the Advisory Committee on Immunizations Practices (ACIP). MMW R Morb Mortal W kly Rep 2001;50:1-25.

18. Centers for D isease Control. En:Atkinson W, W olfe C, Ed. Epidemiology and prevention of vaccine-preventable diseases. Seventh Edition. Atlanta (GA): CDC, 2002:230-250.

19. Mack TM. Smallpox in Europe, 1950-1971.J Infect D is 1972;125:

161-169.

20. Mack T.A different view of smallpox and vaccination. N Engl J Med 2003;348(5):460-463.

21. W orld Health 0 rganization. W HO Advisory Committee on Variola Virus Research. Report of the Third Meeting. Ginebra, Suiza:W HO, December 2001. Disponible en: www.who.int/emc.

22. W orld Health $O$ rganization. W HO Smallpox eradication: Destruction of Variola virus stocks-W HO Advisory Committee on Variola Virus Research. Report by the Secretariat of the Fourth Meeting. Ginebra, Suiza:W HO, D ecember 2002. D isponible en: www.who.int/emc. 23. Barquet N , Domingo P. Smallpox:The triumph over the most terrible of the ministers of death.Ann Intern Med 1997:127:635-642.

24. Rosenthal SR, Merchlinsky M, Kleppinger C. D eveloping new smallpox vaccines. Emerg Infect $D$ is 2001;7:7.

25. Lane JM, Rubén FL, N eff JM, Millar JD. C omplications of smallpox vaccination, 1968: Results of ten statewide surveys. J Infect $D$ is 1970;122:303-309.

26. Schraeder TL, Campion EW. Smallpox vaccination-the call to arms. N Engl J Med 2003;348(5):381-382.

27. Sepkowitz KA. How contagious is vaccinia? N Engl J Med 2003;348(5):439-446.

28. Bozzette S, Boer R, Bhatnagar V, Brower JL, Keeler EB, Morton SC et al. A model for a smallpox-vaccination policy. N Engl J Med 2003;348(5):416-425. 
29. Blendon RJ, DesRoches C, Benson JM, Herrmann MJ,Taylor-Clark K, W eldon KJ.The public and the smallpox threat. N Engl J Med 2003;348(5):426-432.

30. Halloran ME, Longini IM, N izam A, YangY. Containing bioterrorist smallpox. Science 2002;15:298(5597):1428-1432.

31. Connolly C. Two Hospitals refuse call to vaccinate workers. W ashington Post 2002 December 18;A2.
32. Gettleman J.Two hospitals refuse to join Bush's plan for smallpox. $\mathrm{N}$ ew York Times 2002 December 19;A2.

33. Hanrahan JA, Jakubowcyz M, D avis BR.A smallpox false alarm. N Engl J Med 2003;348(5):467-468.

34. Bartlett J, Borio L, Radonovich L, Samia Mair J, 0 'Toole T, Mair M et al. Smallpox vaccination in 2003: Key information for clinicians. Clin Infect D is 2003;36:883-902. 